\title{
Production-Oriented Approach to Reading: Writing-Oriented Reading Instruction*
}

\author{
GU Yu-lan \\ Sichuan University of Arts and Science, Dazhou, China
}

\begin{abstract}
WORI is the Production-Oriented Approach to reading in the TEFL context of China. It is intended to enhance English learners' proficiency in writing and reading. By asking questions to draw learners' attention to the professional writers' choices concerning organization, development, style, and diction, teachers explicitly guide learners to observe, analyze, study, apperceive, so as to learn about their writing thinking and strategies. By designing a variety of reading-to-write tasks, teachers endeavour to activate learners' writing thinking developed in writing-oriented reading activities to have such writing thinking fixed in mind and internalized. The WORI also fosters English learners' autonomy of sustaining development in reading, writing, as well as their English learning.

Keywords: Writing-Oriented Reading Instruction, reading-to-write tasks, writing thinking
\end{abstract}

\section{Introduction}

Analyzing the requirements of the job market for English learners and the language output psychological mechanism, Wen (2008) proposed the output-driven hypothesis, finally named Production-Oriented Approach (POA), intending to solve the problems caused by the English curriculum and teaching, which is focused on receptive skills. The POA, however, targeted the intermediate and advanced learners (Wen, 2015), does not benefit other Chinese EFL learners, who suffer even more from the Chinese input-focused English teaching and are also in urgent need of improving their English. To make the POA facilitate more English learners, the paper tends to explore the POA to reading - the Writing-Oriented Reading Instruction (WORI).

\section{Writing-Oriented Reading Instruction}

Intended to be practical, most skill courses for English majors set by Wen (2008) are production-oriented, written or spoken, and therefore too challenging to be effectively applied in many Chinese colleges whose students are not intermediate and advanced English learners. The written output course alone, for example, is to develop English learners' listening-to-write performance, reading-to-write performance, and reading-to-speak-and-to-write performance, which is obviously beyond the reach of most English learners. To make it less difficult, this course can be subdivided into listening-to-write course, reading-to-write course,

\footnotetext{
* Acknowledgements: This paper is supported by the Education Department of Sichuan Province, in the name of "2011 Construction Project of Higher Education Quality-Writing-Oriented Reading Instruction" and by Sichuan University of Arts and Science (Grant No.: 2013JZ13).

GU Yu-lan, associate professor, M.A., School of Foreign Languages, Sichuan University of Arts and Science.
} 
reading-to-speak-and-to-write and reading-to-write-and-to-speak course. WORI is the reading-to-write course, that is, the Production-Oriented Approach to reading.

WORI is superficially about reading. Its ultimate purpose is, however, not merely to improve learners' reading performance, but to comprehensively develop their reading, writing, and learning autonomy. WORI is meant to develop English learners' writing thinking by explicitly guiding learners to observe, analyze, study, and understand the writers' strategies and skills in diction, sentence making, paragraph development, and discourse organization in class, which simultaneously and consequently lead up to learners' understanding of what is read. Such reading instruction will help learners develop their writing thinking without too much struggling. Meantime, WORI is intended to activate the "acquired"1 writing thinking and put it into practice by designing a variety of reading-to-write tasks based on what is read, which will deepen learners' understanding of the reading material. WORI eventually fosters English learners' autonomy of sustaining development in reading, writing, and language learning, for the learning abilities developed are more likely to transfer.

WORI differs from the traditional understanding-oriented reading instruction in that it is not designed to tell learners what the reading material means, or to present what an important word, phrase, or sentence pattern may mean independent from a specific context, but is meant to guide learners' attention and efforts to the writers' rhetorical choices of such as contents, organization, development, and style, so as to learn about words, phrases, sentence patterns, and eventually production both theoretically and practically, which brings about learners' deep and complete understanding of the texts. To sum up, WORI is production-oriented, with thorough understanding of the input as its natural reward.

WORI varies from sample teaching occasionally carried out in the traditional writing class, for it does not concentrate itself at one time on the illustration of one writing variable, but, seemingly not individually targeted, is meant to be complete and comprehensive, exploring how each writing variable in a specific context co-works and collaborates with other variables to make a unified, coherent, and well-developed text, during which learners know about words, phrases, structures, and writing practically, and eventually acquire how to make the best of what they know about language and writing skills to express themselves clearly and completely. To conclude, WORI is aimed at comprehensive acquisition of effective production and producing through classroom reading instruction, with practical knowledge of the English language as its natural side products.

WORI distinguishes itself from summary writing, book reports writing, continuation tasks, or other reading-and-writing tasks in that learners do not read without teachers' guidance, do not write to show how well they understand what is read, and do not occasionally or mechanically imitate specific cases of word use. Instead, it helps with learners' reading and writing by guiding them to read as writers and to learn about how the professional writers make the most of the English language and writing skills to express themselves, comprehensively developing learners' writing thinking. And it designs writing tasks for learners to endeavour to write as the professional writers, to imitate their approaches to efficient production, to put into practice the writing thinking they have acquired in reading, and to find out how far they have to go before they are able to

\footnotetext{
${ }^{1}$ Here the writer prefers "acquire" to "learn", for learners get to know about how to write without making conscious efforts or without writing instructions. They simply feel that it works that way as what they have read. With clear writing instructions and writing tasks to be followed, learners will be confronted with less difficulties, but will have more fluency and proficiency in writing.
} 
write as the professionals do. To summarize, WORI is meant to help learners to read and write as professional writers do, apperceiving the expert approaches to writing by reading and writing.

\section{Instructions and Procedures}

Within the course framework of Wen (2008), the skill courses for English majors are designed to develop their autonomy in individual language skills, while the written output course is an integrated course aimed at the comprehensive development of learners' listening, reading, speaking, writing, and critical thinking. Less advanced learners, therefore, may have difficulty in moving on directly from the learning of a single language skill to the development of integrated language skills. Writing-oriented reading, aimed at the development of writing and reading, however, is less difficult, for it agrees with the $i+1$ principle, pushing learners to move on from one-skill learning to two skills to bridge the gap between learners and the integrated course, preparing them for further development. During WORI, teachers act like a scaffold, forwarding learners from a lower learning stage to a more advanced one by teaching them how to develop their writing and reading simultaneously through their independent reading. To achieve this goal, teachers are advised to do as follows.

\section{Elucidating the Perception of WORI by Comparison and Contrast}

Before instructing writing-oriented reading, teachers per se must distinguish writing-oriented reading from understanding-oriented reading, and exemplify it to learners, getting them mentally and cognitively ready for WORI.

Teachers may film in advance a micro lecture of the WORI and of the understanding-oriented reading instruction for the same text or paragraph, and play them in class, or respectively perform these two different instructions, guiding learners to compare and contrast their teaching contents, methods, objectives, and possible results, as well as their requirements for learners. Whatever they do, teachers need to make it clear to students (1) that the teaching content of WORI is not the understanding of the reading material or important words, phrases, and sentence patterns in it, but the writers' choices of key words, phrases, sentence patterns, subjects, and the effects of such choices; (2) that teachers are not to tell learners about the reading material or the lexical and syntactical matters, but guide learners to observe, study, and learn the semantic prosody of such lexical and syntactical items in context and to apperceive the experts' writing thinking, techniques and approaches, and to understand the text thoroughly; (3) that WORI is not only aimed at the understanding of the text, the increase in vocabulary quantity, and the development of skills in distinguishing the right answer from what is offered, but, more importantly, the progressive development of writing thinking, the flexibility of using lexical and syntactical knowledge to express one's idea, and the autonomy of developing one's reading and writing by independent writing-oriented reading; and (4) that WORI is not to check teaching and learning mostly by dictating the new words, or getting learners to pick out the "right" answer, which though can be one checking means, but often having them answer questions about the understanding and the thinking flow, and by designing a variety of reading-to-write tasks, which can be well tackled only with real understanding of the text, its development and its organization.

In one word, teachers and learners must agree that writing-oriented reading challenges both of them, that teachers must design questions which make learners read, think, and explore in the context, and that students 
must actively involve themselves in reading and in classroom activities, instead of sitting there, receiving whatever is transmitted by teachers.

\section{Developing Writing Thinking Through Writing-Oriented Reading Instruction}

Reading benefits writing in various ways. Raimes (1983), Wyrick (2011) talked about how reading promotes writing. Raimes (1983, p. 51) thought reading gets learners "familiar with the vocabulary, idiom, sentence patterns, organization flow, and cultural assumptions of native speakers of the language", and, more importantly, it helps learners understand what professional writers "chose to do with the content" (Raimes, 1983, p. 51). According to Wyrick (2011, pp. 179-180), reading may give learners bright ideas for their writing, shed some light on its development, encourage learners to use language in new ways, and get learners more aware of the writing process. Butterfield (1986, as cited in Timothy, 2004, p. 236) believed good writers are "more attentive to the structure of text" and tie ideas together within and between paragraphs with conjunctions, references and lexical tools. Reading provides good models for writing (Harmer, 2000, p. 68), and facilitates writing. Certain English teaching in China, however, has convinced that understanding-oriented reading and instruction do not help with learners' writing development, at least not so much with the balanced development between reading and writing, which eventually prohibits learners' sustainable development. This is why writing-oriented reading and reading instruction are advocated. The instructions and procedures of writing-oriented are illustrated from the following perspectives.

Word choice and sentence making. Words are the most basic unit of writing, but careless accumulation of words does not make effective communication. William K. Zinsser (2001, p. 34) suggested writers take time to seek for the right word. "The right word" here refers to not only the grammatically and syntactically correct words, but also specific, definite, and concrete words for details, as well as general and abstract words for overall statements. One simple word may make much difference in the final effect. It is true of sentences. Two sentences which appear to convey the exactly same meaning may indicate different things, creating two totally different atmospheres. It is never too careful to choose the right words and effective sentence patterns.

Take the following excerpt for example:

I walked alongside my father, clutching his right hand. All my clothes were new: ... They did not make me happy, however, as this was the day I was to be thrown into school for the first time.

"Why school?" I asked my father. "What have I done?"

..."School's not a punishment. It's a place that makes useful men out of boys. Don't you want to be useful like your brothers?"

I was not convinced. I did not believe there was really any good to be had in tearing me away from my home and throwing me into the huge, high-walled building. (Yang, Xu, \& Lu, 2010, p. 2)

To perform WORI, teachers may design the following questions: (1) Why does the author use "clutch" instead of "hold" in the first sentence? (2) What does "What have I done?" imply? (3) Can "They did not make me happy." be replaced by "I was not happy."? What is the delicate difference? (4) Why does the author use "be thrown into school" and "throwing me into" instead of "send/take me to school"? Why does the author use "the huge, high-walled building" to refer to school? What does "tearing me away from my home" indicate? and (5) Do the sentence "I was not convinced." and the following one "I did not believe..." almost have the same meaning? Does the author go against the writing principle of brevity? Why or why not? 
By exploring these questions in the specific context, learners will come to know that (1) Clutch means hold something tightly, usually because of being afraid or anxious. It is a hyponym of hold, used to describe the little boy's worry and scare on his first school day; (2) The question "What have I done?" is better than other questions simply asking for a piece of information in that it indicates his suspensed fright caused by his imagined punishment (being sent to school) that he had to suffer since he has done something wrong or bad; (3) The author chose to use "They didn't make me happy." to indicate the fright the boy was experiencing, which could not be overshadowed by the pleasure generated by new clothes, new toys, and the like; (4) The author selected "throw" and "tear" to describe the boy's frightened impression of being violently taken away from his home, a safe place, deserted as garbage, and carelessly left in the school, a totally new place like a prison, giving the boy the feeling of helplessness and insecurity; and (5) The sentence "I did not believe..." is indeed the repetition of "I was not convinced.". It seems not to agree with the principe of brevity, but it is actually the author's clever use of repetition to emphasize the boy's dad's reasoning and lecture about going to school did not excite the boy's curiosity, did not convince him of the fact that going to school had nothing to do with punishment.

After answering these questions, learners will not only understand what the text is intended to convey, but also learn how these specific and concrete words and sentences help to call up the image of a little boy who was unwilling to leave his parents and his home for school, and his scare of going to a new place and facing up with new people.

When instructing, if teachers consciously keep steering learners to explore the implied meaning of the chosen words, phrases, and sentences, they will apperceive the importance and possibility of word choice and sentence making, and develop a writing habit of seeking for words, phrases, and sentences conveying what is meant. Then they are likely to do as the professionals do while reading and writing.

Paragraph development. Paragraph development is about the selection of essential details to support and elaborate the main idea of the paragraph, supporting and advancing the theme development of the whole text. Most English learners in China struggle with the problem of "what to write" partially because they do not know how to develop their main idea, do not know what details are essential for the elaboration of what they want to communicate.

Teachers' WORI of the following paragraph may help them learn to develop their ideas:

Nor was he simply an entertainer. He wrote about the marvels of tomorrow with such precise, indisputable detail that he was taken seriously. Learned societies argued with him. Mathematicians spent weeks checking his figures. When his book about going to the moon was published, 500 people volunteered for the next expedition. France's famous Marshall Lyautey once said that modern science was simply a process of working out in practice what Jules Verne had envisioned in words. (Xu \& Yang, 2011, p. 321)

When instructing learners to read this paragraph, teachers may ask (1) Why did not the author simply use "He was not simply an entertainer"? (2) Besides an entertainer, what else was Jules Verne? (3) Who took Verne and his books seriously and how? and (4) Why did the author quote the words of Marshall Lyautey at the end of this paragraph?

The first question guides learners to notice the textual function of "nor" and the inverted sentences - connecting learners with what have been talked about in the foregoing paragraphs and to anticipate something new. The second question motivates them to find more about Verne. The third question drives them to 
know the following sentences support the main idea of the second sentence. The fourth question gets them to understand that the quoted sentence concludes and emphasizes Verne's and his books' significant position in science. Then, learners will realize that the author develops this paragraph by the pattern of "general statement-supporting details-summary/conclusion", and that illustration is an efficient strategy of developing one's main idea.

When dealing with expository essays, if teachers keep asking questions which showcase the logical development of the paragraph, they will stimulate and keep learners' reading curiosity, getting them to read and think actively, and subsequently to notice and understand the development pattern. And learners will get accustomed to reading and writing the same way.

Text organization. Right words, effective sentences, and sound logical help to make unified, coherent, and well-developed paragraphs. They are, however, not everything of a text. To create a good text, these individual paragraphs need organizing logically together. A text is like a paragraph, a longer and more complex one. Teachers, therefore, can guide learners to notice the development of a text as they handle paragraphs, as is to be shown by the following text:

(1) My husband and I just got back from a week's vacation in West Virginia. Of course, we couldn't wait to get there, so we took the Pennsylvania Turnpike and a couple of interstates. ...Getting there certainly didn't seem like half the fun; in fact, getting there wasn't any fun at all.

(2) So, when it was time to return to our home..., I insisted that we take a different route.... The two days it took us to make the return trip were filled with new experiences. ... and we returned home refreshed, revitalized, and reeducated. This time, getting there had been the fun.

(3) Why is it that the featureless turnpikes and interstates are the routes of choice for so many of us? ... Our country has become a nation in search of the quick fix - in more ways than one.

(4) Now instead of later: Americans understood the principle of... But today we aren't so patient...

(5) Faster instead of slower: Not only do we want it now; we don't even want to be kept waiting for it...

(6) Superficially instead of thoroughly: What's more, we don't even want all of it...

(7) When did it all begin,...? Why are we in such a hurry to save time? And what are we going to do with all the time we save...

(8) Don't get me wrong. I'm not saying... I'm not even advocating... But I am saying that... Let's take the time to... Let's rediscover life in the slow lane. (Xu \& Yang, 2011, pp. 114-116)

When instructing learners to read it, teachers can design the following questions: (1) Why does the author tell about their different routes, experiences, and feelings to West Virginia and back home? Do you think she knew why so many Americans choose turnpikes and interstates instead of the countryside roads? If she did, why does she ask the two questions at the beginning of the third paragraph? (2) In how many ways do Americans show their tendency to fix everything quickly? What are they? and (3) Do you think the author really wanted to know when Americans begin to be rushing, why they are busy saving time and what they are going to do with the time saved? What does she want to do by asking the three questions? Does she mean to indicate that Americans should grow their own vegetables and make their own clothes or even stop using credit cards? What does she want Americans to do?

The first group of questions draws learners' attention to the textual function of rhetorical questions. The second group of questions leads learners to find out in what ways Americans search for quick fix. The third group once again directs learners to the transitional function of rhetorical questions. These three groups of questions mark the three parts of the text: the introduction, the body, and the end. 
Then, teachers can design questions and activities for learners to understand the connection among the paragraphs. Teachers ask "Why didn't the author and her husband choose the Pennsylvania Turnpike and interstates back home?", directing learners' attention to the transitional function of "so" starting the second paragraph. Before learners read the three features in details, teachers may rewrite the first sentences of Paragraphs 4, 5, and 6, and then put the three features randomly together, telling learners to rearrange them, and compare with the original arrangement. It is clear that the WORI helps learners understand how the author organized the three seemingly parallel features and made them coherent by drawing learners' attention to the textual function of the syntactic feature of "not only...but also", not simply repeating its syntactical feature when "not only" is placed at the beginning of a sentence, as understanding-oriented reading instruction often does. Also, teachers may get learners to notice the transition function of the parallel structures. Instructing learners to read texts this way will turn out to be much more efficient than understanding-oriented reading instruction.

More significantly, such instruction promotes the coherence of their writing. Good writers make better use of cohesive ties, such as conjuctions, reference, and lexical ties, and produce more of them (Butterfield, 1986, as cited in Timothy, 2004). Teachers' WORI helps learners get familiar with such cohesive devices, and eventually learn to employ them to shape their writing.

To conclude, WORI guides learners to do analytical reading of professional essays for them to notice and appreciate the logical flow among paragraphs and the approaches of realizing such coherence, and to develop their ability of independent reading, and writing as well. William K. Zinsser (2001, p. 35) recommended learners develop a habit of reading masters, figure out how they wrote, and imitate to cultivate the best models. His words explain why writing-oriented reading instruction and reading-to-write tasks work together to promote learners' writing and reading. And its more far-reaching effect is that such reading and writing abilities are more likely to be transferred.

As it is, not all texts are featured by specific and typical examples of word choice, sentence making, paragraph development, and text organization. It is, however, not the individual writing examples and their effects, that learners are intended to learn about, but how and why professional writers make the choices they have made and what differences such decisions make. Teachers will help learners a lot with their writing and reading as long as they keep guiding learners to observe, think, and explore all kinds of choices professional writers have made and the reasons as well as the effects of such choices, and design a variety of writing tasks for learners to bring into practice what they have learned in reading.

\section{Activating Writing Thinking Through Reading-to-Write Tasks}

Obviously, implementing WORI in class is not enough to improve learners' writing. For, on the one hand, class time is limited, and on the other hand, learners may know what and how to write effectively with the help of WORI, but they may not write that way. Thus, WORI essentially involves writing-oriented reading instructions and reading-to-write tasks as well, both inside and outside class.

To put it another way, writing-oriented reading instruction needs to be combined with reading-to-write tasks in the interest of learners' balanced development of reading and writing, so as to promote learners' writing and reading. When carrying out writing tasks, learners will recognize their language deficiency. With 
writing tasks at hand and the feeling of language inadequacy, they will be motivated and try harder to improve themselves, and get more sensitive to language and to the language use of professionals (Huang, 2002, p. 16). Without writing tasks, they would focus mainly on the meaning, ignoring the form conveying such meaning (Huang, 2002, p. 9; Gu, 2015, p. 139), and would stop at the point where they understand what it is, but would not proceed to explore why and how it is what it is, subsequently ending up able to recognize and understand, sometime only partially, what they read, but unable to express what they want to, which, though, they do not have much difficulty in understanding when reading them. This is why understanding-oriented reading instruction does not promise the balanced development of learners' writing and reading.

Indeed, reading-to-write tasks help with learners' writing and reading. Simple reading and writing activities, however, do not guarantee the development of their higher literacy, the literacy "in which information from a source text is not only understood on its own terms, but is transformed in the hands of the writer" (Flower, Stein, Ackerman, Kantz, McCormick, \& Peck, 1990, p. 4). Then, what reading-to-write tasks can teachers employ after WORI to develop learners' higher literacy?

Many different reading-to-write tasks have been designed and studied by teachers and researchers. According to the difficulty, they can be classified into three groups: beginning, intermediate, and advanced reading-to-write tasks, each of which includes a variety of activities.

Beginning reading-to-write tasks. In China, summaries and book reports are two types of earliest writing tasks following reading. They, however, were not designed as reading-to-write tasks, but as a means of checking whether learners have read as required. Even so, summary writing was proved able to enhance learners' reading and writing ( $\mathrm{Li} \& \mathrm{lv}, 2002$ ), and book report writing was verified able to enhance reading (Zhou \& SIRIYOTHIN, 2010).

A third type is imitating. Francine Prose (2006, p. 9) thought learning to write by reading is something like pretending to be able to read by memorizing and eventually crossing the line from pretending to being actually able to. Imitating, first of all, helps solve learners' problem of not knowing what to write about and not knowing how to write. Teachers can assign reading tasks, and then tell them to produce their own by imitating the subjects, contents, styles, or purposes. For example, teachers can tell learners to imitate A Private Conversation (Alexander \& He, 1997, p. 12) to write something about listening to a lecture, going to a concert, or watching a football game.

Texts or paragraphs with typical patterns of idea development are especially good for imitation. English majors in China suffer from deficiency of critical thinking (Huang, 1998, p. 1). By mimicking their development patterns and familiarizing themselves with effective organizing strategies and approaches, learners will come to feel comfortable with paragraph development and organization. Teachers, for instance, may have learners read the Aesop's fable The Flies and the Honey-Pot and assign them to write an essay with the same theme illustrated by a modern example.

Such imitation is like Prose's pretending to be able to read by memorizing (Prose, 2006, p. 9). Learners' efforts made to imitate professionals' development patterns will become a fixed behaviour pattern and writing thinking, which will be further consolidated by intermediate reading-to-write tasks, so as to be internalized.

Intermediate reading-to-write tasks. After such beginning reading-to-write tasks, teachers need to design more challenging tasks, such as detailed writing, rewriting, and continuation tasks. Detailed writing 
refers to the writing task of offering the details disregarded in the original texts or even expanding the original text as a whole, exactly keeping consistent with its original purpose, theme, style, and development patterns. For instance, teachers can tell learners to expand A Clear Conscience (Alexander \& He, 1997, p. 202) to explain why the "thief" first kept and then returned the butcher's money.

Rewriting is a little bit different from detailed writing in that learners do not necessarily keep exactly consistent with the original text. When rewriting, learners may simply change the style, the presentation method, the development pattern, part of the contents, or change everything, even the ideas or arguments of the original text as long as the rewritten product as a whole makes sense. Teachers may assign learners a task of rewriting a text from a different point of view, rewriting its end, redesigning its plot, resetting its context, reorganizing a paragraph or the whole text to make it more effective, adapting a novel, a play, a story, and even a song lyrics into something else which transmits approximately the same themes, manifesting a similar problem from a different perspective, or supporting a totally different opinion. It must be noticed that no researchers have confirmed the effectiveness of this type of reading-to-write tasks. Teachers, therefore, can take care to collect data to testify to or negates its effectiveness while having learners do such writings.

Continuation tasks are writing tasks which require learners to write a reasonable ending for a text whose ending has been cut off by design and while doing so, learners cannot change the original style, type, and logic (Wang, 2012). Wang (2012) and other researchers (Wang \& Qi, 2013; Wang, 2014; M. Wang \& C. M. Wang, 2014; Jiang \& Chen, 2015; Wang, 2015) have mainly studied about the continuation tasks of English and Chinese narratives and confirmed the effectiveness of this reading-to-write task. Teachers can try applying the continuation tasks to other types of writing, and, try getting learners to write its beginning part, or even its body part, for a text. Whatever is to be continued, learners have to understand the original text completely to make their products consistent with it logically. The continuation tasks are, therefore, most efficient to train learners' conception and awareness of the unity and consistency principle of texts, and to develop their writing thinking and the overall awareness of the text as a whole.

Advanced reading-to-write tasks. Next teachers can design more challenging and advanced reading-to-write tasks, like, "prompted" essays and the summary-and-response essays.

"Prompted" essays require learners to express their own ideas about a specific topic introduced in or by written passages (Wyrick, 2011, p. 442), by pictures or cartoons. "Prompted" essays allow learners much more freedom of what is written, but offer little (the prompt and their previous knowledge about the topic and of essay writing) for them to refer to, to imitate or to follow. This is what makes "prompted" essays advanced and challenging. More advanced and challenging are the summary-and-response essays. The task of writing summary-and-response essays requires learners, first of all, thoroughly understand what the prompt essay is intended to convey, how it does it, and whether it does it effectively. Then learners are expected to write a summary for the prompt essay as the introduction part of the summary-and-response essay, and move on to argue with a reasoned defence why they agree or disagree with the author on his or her idea presented in the selected essay (Wyrick, 2011, p. 442). Or alternatively, learners may be told to argue about the reasoning of the prompt essay, or its examples cited to support a sub-idea or its supporting sub-ideas, for example, whether their reasoning is convincing enough, why or why not, and whether its examples are typical enough, and whether its sub-ideas presented are complete and thorough. All these responses ask for learners' critical thinking and need 
them to put in perspective what is presented in the prompt essay. Thus, writing "prompted" essays and summary-and-response essays exercise learners' perception, thinking, reasoning, and expressing, that is, learners' analytical reading and writing. It is why the type of reading-to-write tasks is most helpful with learners' reading and writing.

As $\mathrm{Wu}$ (2014) pointed out, studies about reading-to-write tasks, especially the advanced ones, have been one of the burgeoning subjects in language teaching and testing. Internationally, it has been long since reading and writing tasks were combined together in their language teaching (Flower et al., 1990; Asencion, 2004; Weigle, 2004, as cited in Zhang \& Zeng, 2009), for instance, in entrance or exit examinations for composition classes, college entrance examinations (Wyrick, 2011). With the development of English teaching and testing in China, many important English examinations have begun to employ reading-to-write tasks as their writing type. In the college entrance examination of 2007, examinees in Guangdong Province, a province in the south of China, started to be asked to write a summary for a passage, and then write a composition about something mentioned in the passage. In 2013, "FLTRP Cup" English Writing Contest began to include reading-to-write tasks as one of its alternative question types. And from 2016 on, TEM-4 and TEM-8 (Test for English Majors-Band 4 or 8 ) began to adopt such writing tasks. Wen (2008) has analyzed the language requirements of the job market for English learners and decided that language production skills play an ultimate role in one's job. Some researchers (Zhang \& Zeng, 2009; Zhang, Zeng, \& Zhang, 2010) have presented experimental confirmation of the effectiveness of writing the summary-and-response essays in large-scale writing assessment in China. Therefore, teachers can feel free to design such writing tasks more often to prepare learners for important examinations and the job market.

The reading-to-write tasks are best to have something to do with the texts teachers have instructed learners to read in the writing-oriented way, and then with texts they have to read independently, especially for a new writing task type. The connection with what they have read will make writing tasks less difficult and challenging, which helps build learners' confidence. And teachers must assess learners' products promptly and carefully, identifying their merits and demerits. Without timely assessment, reading-to-write tasks have the risk of degenerating into writing tasks designed as checking means. Teachers can even try tackling reading-to-write tasks themselves and share with learners their products, writing process, writing difficulties they encounter, and strategies they employ to overcome them. By writing in person, teachers may have better conception of what needs lecturing about in class to help learners with their writing.

\section{Conclusion}

Timothy (2004, p. 229) said humans "have no natural predisposition for reading and writing" and "children need explicit instruction and modelling to become proficient at reading and writing". His words are the underlying theory of WORI, which is designed to provide for such explicit guidance and samples to learners and to improve their proficiency at English writing and reading. By asking questions to draw learners' attention to the professional writers' choices concerning organization, development, style, and diction, teachers explicitly guide them to observe, analyze, study, explore, apperceive, and so as to learn about their writing thinking and approaches. By designing a variety of reading-to-write tasks, teachers endeavour to activate learners' writing thinking developed in writing-oriented reading activities to have such writing thinking fixed and internalized in 
learners' mind. The WORI also fosters English learners' autonomy of sustaining their development in reading, writing, as well as their English learning, for abilities developed with its help are more likely to be transferred.

\section{References}

Alexander, L. G., \& He, Q. X. (Eds.). (1997). New concept English 2 (New ed.). Beijing: Foreign Language Teaching and Research Press; HK: Longman Asia Ktd.

Asencion, Y. (2004). Validation of reading-to-write assessment tasks performed by second language learners (Ph.D. dissertation, Northern Arizona University, Flagstaff).

Butterfield, J. (Ed.). (1986). Language, mind, and logic. New York: Cambridge University Press.

Flower, L., Stein, V., Ackerman, J., Kantz, M. J., McCormick, K., \& Peck, W. C. (1990). Reading-to-write: Exploring a cognitive \& social process. New York: Oxford University Press.

Gu, Y. L. (2015). A review of studies of Chinese college English reading teaching in the 21st century. Sichuan University of Arts and Science Journal, 25(5), 134-141.

Harmer, J. (2000). How to teach English. Beijing: Beijing Foreign Language Teaching and Research Press.

Huang, Y. S. (1998). Deficiency of critical thinking. Foreign Languages and Their Teaching, 7, 1, 19.

Huang, Y. S. (2002). Frequent reading and writing-Secrets of English learning. Journal of Foreign Languages, 142(6), 13-17.

Jiang, L., \& Chen, J. (2015). The continuation task: Effects on written accuracy, complexity and fluency. Modern Foreign Languages, 38(3), 366-375.

Li, M. Y., \& Lv, Q. (2002). Improving reading through writing. Shangdong Foreign Languages Teaching, 6, 41-44.

Prose, F. (2006). Reading like a writer: A guide for people who love books and for those who want to write them. New York: Harper Collins Publishers.

Raimes, A. (1983). Techniques in teaching writing. New York: Oxford University Press.

Timothy, B. J. (2004). The psychology of language. Beijing: Beijing University Press.

Wang, C. M. (2012). The continuation task: An effective approach to improving L2 learning . Foreign Language World, 152 (5), 2-7.

Wang, C. M. (2015). Why does the continuation task facilitate L2 learning? Foreign Language Teaching and Research, 47(5), 753-762.

Wang, C. M., \& Qi, L. X. (2013). A study of the continuation task as a proficiency test component. Foreign Language Teaching and Research, 45(5), 707-718.

Wang, M., \& Wang, C. M. (2014). The effects of alignment in continuation tasks. Modern Foreign Languages, 34(4), $501-512$.

Weigle, S. C. (2004). Integrating reading and writing in a competency test for non-native speakers of English. Assessing Writing, 9, 27.

Wen, Q. F. (2008). On the out-driven hypothesis and reform of English-skill courses for English majors. Foreign Language World, $125(2), 2-9$.

Wen, Q. F. (2015). Developing a theoretical system of production-oriented approach in language teaching. Foreign Language Teaching and Research, 47(4), 547-558.

William, S. J. R., \& White, E. B. (2009). The elements of style (4th ed.). London: Longman.

Wu, Y. (2014). Exploring test takers' source use strategies in an EFL reading-to-write integrated task . CAFLE, 159(5), 63-69.

Wyrick, J. (2011). Steps to writing well with additional readings. Boston MA: Wadsworth, Cengage Learning.

Xu, K. R., \& Yang, L. M. (Eds.) (2011). Contemporary college English 2 (2nd ed.). Beijing: Foreign Language Teaching and Research Press.

Yang, L. M., Xu, K. R., \& Lu, P. M. (Eds.) (2010). Contemporary college English 1 (2nd ed.). Beijing: Foreign Language Teaching and Research Press.

Zhang, X. L., \& Zeng, Y. Q. (2009). Construct validation of reading-to-write tasks in large-scale writing assessment in China. Journal of PLA University of Foreign Languages, 32(1), 56-61.

Zhang, X. L., Zeng, Y. Q., \& Zhang, J. (2010). Validation of a large-scale reading-to-writing test: Evidence from multi-faceted Rasch model analysis. Journal of PLA University of Foreign Languages, 33(2), 50-54.

Zhou, L., \& SIRIYOTHIN, P. (2010). Effects of source-based writing tasks on Chinese EFL students' reading comprehension. Foreign Languages and Their Teaching, 6, 53-56.

Zinsser, K. W. (2001). On writing well: The classic guide to writing nonfiction (25th anniversary ed.). New York: Harper Collins Publishers. 